NASA/TM-2003-212211
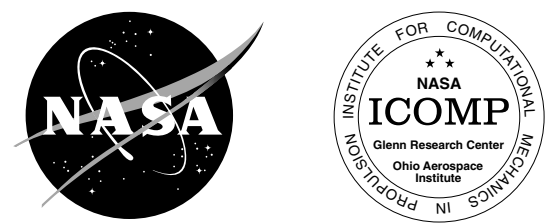

\title{
Real Gas Effects on the Performance of Hydrocarbon-Fueled Pulse Detonation Engines
}

Louis A. Povinelli

Glenn Research Center, Cleveland, Ohio

Shaye Yungster

Institute for Computational Mechanics in Propulsion, Cleveland, Ohio 
Since its founding, NASA has been dedicated to the advancement of aeronautics and space science. The NASA Scientific and Technical Information (STI) Program Office plays a key part in helping NASA maintain this important role.

The NASA STI Program Office is operated by Langley Research Center, the Lead Center for NASA's scientific and technical information. The NASA STI Program Office provides access to the NASA STI Database, the largest collection of aeronautical and space science STI in the world. The Program Office is also NASA's institutional mechanism for disseminating the results of its research and development activities. These results are published by NASA in the NASA STI Report Series, which includes the following report types:

- $\quad$ TECHNICAL PUBLICATION. Reports of completed research or a major significant phase of research that present the results of NASA programs and include extensive data or theoretical analysis. Includes compilations of significant scientific and technical data and information deemed to be of continuing reference value. NASA's counterpart of peerreviewed formal professional papers but has less stringent limitations on manuscript length and extent of graphic presentations.

- TECHNICAL MEMORANDUM. Scientific and technical findings that are preliminary or of specialized interest, e.g., quick release reports, working papers, and bibliographies that contain minimal annotation. Does not contain extensive analysis.

- CONTRACTOR REPORT. Scientific and technical findings by NASA-sponsored contractors and grantees.
- CONFERENCE PUBLICATION. Collected papers from scientific and technical conferences, symposia, seminars, or other meetings sponsored or cosponsored by NASA.

- SPECIAL PUBLICATION. Scientific, technical, or historical information from NASA programs, projects, and missions, often concerned with subjects having substantial public interest.

- TECHNICAL TRANSLATION. Englishlanguage translations of foreign scientific and technical material pertinent to NASA's mission.

Specialized services that complement the STI Program Office's diverse offerings include creating custom thesauri, building customized databases, organizing and publishing research results ... even providing videos.

For more information about the NASA STI Program Office, see the following:

- Access the NASA STI Program Home Page at http://www.sti.nasa.gov

- E-mail your question via the Internet to help@sti.nasa.gov

- Fax your question to the NASA Access Help Desk at 301-621-0134

- Telephone the NASA Access Help Desk at 301-621-0390

- Write to:

NASA Access Help Desk

NASA Center for AeroSpace Information 7121 Standard Drive

Hanover, MD 21076 
NASA/TM-2003-212211

ICOMP-2003-02
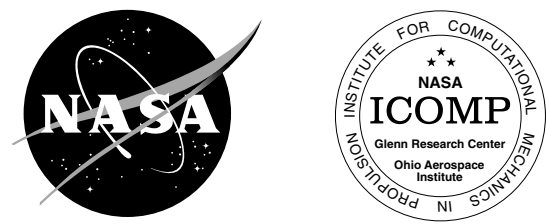

\section{Real Gas Effects on the Performance of Hydrocarbon-Fueled Pulse Detonation Engines}

Louis A. Povinelli

Glenn Research Center, Cleveland, Ohio

Shaye Yungster

Institute for Computational Mechanics in Propulsion, Cleveland, Ohio

Prepared for the

41st Aerospace Sciences Meeting and Exhibit

sponsored by the American Institute of Aeronautics and Astronautics

Reno, Nevada, January 6-9, 2003

National Aeronautics and

Space Administration

Glenn Research Center 
Available from

NASA Center for Aerospace Information 7121 Standard Drive

Hanover, MD 21076
National Technical Information Service 5285 Port Royal Road Springfield, VA 22100

Available electronically at http://gltrs.grc.nasa.gov 


\title{
REAL GAS EFFECTS ON THE PERFORMANCE OF HYDROCARBON- FUELED PULSE DETONATION ENGINES
}

\author{
Louis A. Povinelli* \\ National Aeronautics and Space Administration \\ Glenn Research Center \\ Cleveland, Ohio 44135 \\ Shaye Yungster ${ }^{\dagger}$ \\ Institute for Computational Mechanics in Propulsion \\ Cleveland, Ohio 44135
}

\begin{abstract}
This paper presents results for a single-pulse detonation tube wherein the effects of high temperature dissociation and the subsequent recombination influence the sensible heat release available for providing propulsive thrust. The study involved the use of ethylene and air at equivalence ratios of 0.7 and 1.0. The real gas effects on the sensible heat release were found to be significantly large so as to have an impact on the thrust, impulse and fuel consumption of a PDE.
\end{abstract}

\section{INTRODUCTION}

In our previous publication (ref. 1) it was shown that the high detonation temperatures associated with hydrocarbon-air and hydrogen-air mixtures caused a substantial amount of dissociation, and was accompanied by high concentrations of intermediate species. This process was accompanied by approximately an $11 \%$ decrease in the amount of energy available for thrust relative to a ramjet. The consequence of this loss was to reduce the thermal efficiency of the PDE below the value of the Brayton cycle efficiency at low values of inlet (ram) air temperature ratios.

${ }^{*}$ Chief Scientist, Turbomachinery and Propulsion Systems Division, Fellow AIAA.

${ }^{\dagger}$ Senior Research Associate, Ohio Aerospace Institute, Senior Member AIAA.
The effect of stoichiometric propane-air dissociation loss on the performance parameters of a PDE was calculated as a function of temperature ratio as well as Mach number ( 0 to 5$)$ in reference 2 . The conditions investigated were for an ideal PDE (isentropic inlet and nozzle) at an altitude of $33,000 \mathrm{ft}$ with inlet pressure of 3.8 psia and temperature of $400{ }^{\circ} \mathrm{R}$. In these calculations, both the PDE and the Brayton (gas turbine) cycle had the same ram compression, but the Brayton had additional compression from a mechanical compressor. Therefore, at a given flight Mach number, the PDE has a lower temperature at the detonation chamber entrance than does the turbojet.

The thermodynamic cycle calculations in reference 2 show that (a) the PDE had higher specific thrust than a ramjet up to Mach 2.3 and (b) the PDE had higher performance than a turbojet over a wider Mach range, provided that the mechanical compression ratio in the turbojet was less than 4 . The advantage of the PDE disappears as the mechanical compression ratio of the turbojet exceeds 4 . Some advantages of a combined PDE/Ramjet cycle where the PDE provides static thrust and acceleration with ramjet takeover at Mach 2.5 to 3 and scramjet operation at Mach 5 have been discussed in reference 2 . 
Since the products of the detonation process persist in the chamber for a short, but finite length of time prior to flowing out through the exhaust, we studied the effect of recombination on the sensible heat release (ref. 3). Unsteady, axisymmetric finite-rate chemistry computations were carried out for an open ended tube filled with hydrogen-air mixtures at standard conditions. Hydrogen-air mixtures were used due to the complexities of finite rate chemistry modeling for hydrocarbon-air mixtures and the lengthy computational times required. It was found that the recombination that occurred in the tube reduced the loss of sensible heat. At an equivalence ratio of 1.0 , the sensible heat release loss with recombination was 10.8 percent relative to the heating value of the mixture, whereas, previously, the loss was 16.7 percent when chemical equilibrium was assumed. At an equivalence ratio of 0.6, dissociation effects reduced the sensible heat release by 4.7 percent when equilibrium was assumed, and recombination reduced the loss to 0.6 percent. The study (ref. 3) also showed that the fuel specific impulse with an equivalence ratio of 0.6 was higher than that at an equivalence ratio of 1.0, although the thrust at 0.6 was lower.

In a recent paper (ref. 4) the impulse results of the analysis described above for hydrogen-air were compared to the experimental data obtained at the Air Force Research Labs (ref. 5). The AFRL data, obtained with an opened-ended detonation tube, were shown to be in excellent agreement with our unsteady CFD results over a range of equivalence ratios. In addition, a thermodynamic cycle calculation, with isentropic inlet and exhaust, yielded values that were 200 to 300 seconds of impulse, which may reflect the potential improvement associated with the addition of an exhaust nozzle (ref. 4).
Based on the results obtained with hydrogenair, an estimate was made of the effect of the recombination effect that would occur in propane-air detonation (ref. 6). Since the dissociation losses reduced the sensible heat release by 16.7 percent relative to the heating value with equilibrium chemistry and recombination reduced the loss to 10.8 , a decrement of 5 percent was chosen as the heat loss relative to the lower heating value of the propane-air mixture. The results (ref. 6) showed that the performance of the PDE improved relative to the Brayton cycle. The PDE specific thrust was comparable to the ramjet performance (with no recombination) out to a Mach number of approximately 3.0.

Our work in reference 6 was only an approximation of the recombination based on hydrogen-air chemistry. In the current paper, the degree of recombination that occurs in hydrocarbon-air mixtures is computed using the unsteady, axisymmetric, finite rate method described above (ref. 3).

\section{PHYSICAL MODEL AND NUMERICAL METHOD}

\section{Geometry and Test Gas}

Single-pulse computations were performed for a constant area detonation tube having a length of 1.0 meter and a diameter of 6.6 centimeters. The tube is closed at the head end and the other is open. Ethylene and air having an equivalence ratio of 1.0 and 0.7 , with a temperature of $298 \mathrm{~K}$ were used as the reactants. Calculations were performed for zero forward flight velocity and at a pressure of 1 bar. At the start of the computations, the entire tube is filled with the ethylene-air mixture. The ambient pressure outside the detonation tube is set at 1 bar. 
To initiate the detonation, a small region of high temperature and high pressure nitrogen gas was used. For an equivalence ratio of 1.0, the ignition region was 0.5 centimeters, the temperature was $3000 \mathrm{~K}$ and the pressure was 45 bar. These values are comparable to those used by Kailasanath (ref. 12). It is noted that these values are higher than we used previously with hydrogen-air mixtures (ref. 3), which reflects the higher ignition energy requirements for ethylene-air mixtures. For an equivalence ratio of 0.7 , the ignition region was 1.0 centimeter, the temperature was $3000 \mathrm{~K}$ and the pressure was 50 bar. In this direct initiation method, the shock wave generated at the interface transitions into a Chapman-Jouget detonation wave, as will be shown later.

\section{Computational Method}

Single-pulse finite rate calculations were used to compute the species evolution and resulting thrust and impulse. The analysis was carried out using an in-house developed time-accurate CFD code (refs. 7 and 8). The code solves the axisymmetric Navier-Stokes equations for a non-equilibrium mixture of thermally perfect gases, using an implicit, total variation diminishing (TVD) scheme. It includes a generalized detailed chemistry capability, various options for turbulence models, and steady state or time-accurate algorithms. In the present study, as in reference 3, we excluded viscous effects, thereby using the Euler equations.

The numerical method used for solving the governing set of equations is described in detail in reference 7 and is briefly described here. The equation set is solved using a fully implicit, first-order accurate in time, variable step backward differentiation formula (BDF) method. The numerical fluxes are evaluated using a second order spatially accurate TVD scheme. The resulting equations are then linearized in a conservative manner and solved iteratively, by using a lower-upper relaxation procedure consisting of successive Gauss-Seidel (LU-SGS) sweeps.

The chemical reaction mechanism used for ethylene-air combustion was based on the short mechanism of $\mathrm{Li}$, Varatharajan and Williams (ref. 9) and consists of 36 reactions among 20 species, with nitrogen being treated as an inert, i.e., non reacting species. This chemical modeling was designed to be applied with reasonable accuracy over the range of post-shock temperatures between $1000 \mathrm{~K}$ and $2500 \mathrm{~K}$, pressures between 0.5 and 100 bar and equivalence ratios between 0.5 and 3 . The short mechanism was shown to retain the essence of the chemical pathways and to yield reasonable accuracy with the detailed mechanism of reference 9 .

The inversion of large matrices is avoided by partitioning the system into reacting and nonreacting parts. Therefore, the matrices requiring inversion are of the same size as those in the point implicit methods. The significant advantage of the present method, because it is fully implicit, lies in the fact that it is stable for large CFL numbers, thereby enabling the use of relatively large time steps to minimize computational cost.

In order to maintain high resolution of the wave front at all times, without the use of thousands of grid points, a multi-level, dynamically adaptive grid was implemented in which a very fine subgrid continuously slides along with the detonation wave front (ref. 7).The minimum and maximum grid spacings used in this study were 0.00195 and $1.0 \mathrm{~cm}$.

$\underline{\text { Initiation }}$

\section{RESULTS}

Finite rate chemistry computations were performed for equivalence ratios of 0.7 and 1.0. As shown previously in our computations 
(ref. 3), a high pressure zone is observed at the closed end of the detonation tube. At the interface of this region and the reactants, an expansion wave moves toward the head end and is reflected. At the same time a compression wave moves toward the open end of the tube which compresses and heats the ethylene-air mixture. Following a short induction period, combustion occurs at the interface boundary and shock waves propagate upstream and downstream. The compression waves overtake the shock and cause acceleration. The shock front and the combustion front couple and form a detonation wave.

\section{Detonation Velocity}

The computed detonation velocities for equivalence ratios of 0.7 and 1.0 are shown as a function of time in figure 1 . The velocities are compared to the predictions from the CEA equilibrium code of Gordon and McBride (ref. 10) for a Chapman-Jouget detonation. Following an initial overshoot during the short transient phase, the detonation speeds reach constant values at about 200 microseconds. The detonation speeds are slightly higher than those predicted by the CEA code.

\section{Heat Release}

The corresponding values of the sensible heat release (for both equivalence ratios) are shown in figure 2 for the finite rate calculations and for the chemical equilibrium results from the CEA code. The differences between the finite rate and the equilibrium results when the detonation reaches the end of the tube amount to approximately $6.6 \%$ for an equivalence ratio of 0.7 , and $10.8 \%$ for an equivalence ratio of 1.0. The higher heat release for the finite rate calculations is due to chemical recombination inside the tube.

In our previous work on hydrogen-air detonation with an equivalence ratio of 1.0 (ref. 3), we found a 5.8\% difference between the finite rate calculations and the equilibrium results.

If we now take into account the increase in sensible heat due to recombination in the ethylene-air reaction, and use the thermo cycle code as described in references 6 and 13, the performance of a PDE exceeds that of a ramjet up to a flight Mach number of 3.5.

\section{Pressure Evolution}

The pressure evolution along the tube is shown in figure 3 for an equivalence ratio of 1.0. Initially, a large overshoot occurs when the detonation wave is initiated. The overshoot quickly reduces in value and within $25 \mathrm{~cm}$. the pressure reaches a value which is equivalent to the von Neumann spike as determined from the chemical equilibrium code, CEA. The detonation pressure remains constant over the remaining $75 \mathrm{~cm}$. of the tube, finally decaying as the wave exits the tube.

\section{Flow Properties at Exhaust}

Figure 4 shows the flow properties at the exit of the detonation tube for the ethylene-air mixture with an equivalence ratio of 1.0. The passage of the initial detonation pressure spike and temperature rise occurred at 0.5 milliseconds, followed by a rapid decay within 1 millisecond. The plateau region where the pressure remains at a level value is seen to persist up to about 2.5 milliseconds, after which the pressure decreases further to near ambient levels.

\section{Species Concentrations}

The changes in gas species were determined during the detonation process. In figure 5 , the species concentrations for an equivalence ratio of 1.0 are seen to decay rapidly within 1.5 milliseconds, followed by a lower rate of decay. The concentrations of $\mathrm{O}$ and $\mathrm{OH}$ decline by one order of magnitude in the first 1.5 milliseconds. 
Figure 6 shows the behavior for other species in the ethylene-air reaction. These species have very low concentration values during most of the detonation process except during the ignition phase. It is these changes in intermediate species that indicate recombination occurring within the tube and that give rise to additional sensible heat release.

Since the decay of species occurs so rapidly at 0.5 milliseconds, the use of a longer detonation tube would not be expected to have any significant effect on the heat release.

\section{Force and Specific Impulse Calculations}

The corresponding thrust and impulse for the computations described above are shown in figures 7 and 8 for an equivalence ratio of 1 . Initially, the sharp rise in pressure creates a short duration thrust spike, figure 7 , which is followed by a plateau region of about 2 milliseconds duration and a subsequent decay to zero. It is primarily in this level pressure duration that PDE thrust is generated. The corresponding impulse value is shown in figure 8 . The value of the impulse at its maximum point is 1962 seconds. This value compares well with that of Wintenberger et al. (ref. 11) of approximately 1840 seconds.

\section{CONCLUSIONS}

Real gas effects, i.e., dissociation and recombination in detonating mixtures of ethylene-air mixtures have been calculated using unsteady CFD. These effects were found to be critical in determining the sensible heat of reaction so that propulsion performance calculations can be made for PDE's. The amount of heat release in each propulsion cycle is of critical importance in the comparison of PDE capability relative to other propulsion devices.

It was found that the difference between the finite rate calculations and the equilibrium results for a stoichiometric mixture of ethylene-air was twice as large as those for stoichiometric hydrogen-air at an initial pressure of 1 bar and $298 \mathrm{~K}$.

The sensible heat calculations shown in this paper indicate that the losses associated with a typical hydrocarbon are less than those assumed previously (ref. 6), which were based on hydrogen-air detonation. Use of the new values determined in this paper would increase the competitive range of a PDE, relative to a ramjet, to 3.5 .

Additional work is required to establish the role of a PDE in flight applications, either as a stand alone device or as part of a combined cycle. Some of the issues are associated with static thrust capability, nozzle and exhaust systems and thrust per unit frontal area.

As stated previously (ref. 6), the PDE may have practical advantages over other cycles, i.e., simplicity, fewer moving parts, and lower cost. In order to realize these benefits, the effects of high temperature and high internal flow velocity on heat transfer and viscous losses as well as fatigue and leakage issues related to multi-cycle operation and valving require attention. All of these items need to be addressed and await practical demonstration.

\section{REFERENCES}

1. Povinelli, Louis A., "Impact of Dissociation and Sensible Heat Release on Pulse Detonation and Gas Turbine Engine Performance," NASA/TM-2001-211080, July 2001, also 15th ISABE Symposium Paper 2001-1212, Sept. 2002.

2. Povinelli, Louis A., Lee, Jin-Ho and Anderberg, Michael O., "Role of AirBreathing Pulse Detonation Engines in High Speed Flight," NASA/TM-2001211163, Sept. 2001, also 52nd IAF Congress Paper IAF-01-S.5.01, Oct. 2001. 
3. Povinelli, Louis A. and Yungster, Shaye, "Airbreathing Pulse Detonation Engine Performance," NASA/TM-2002-211575, May 2002, 26th Air-breathing Propulsion Subcommittee, JANNAF Conference, Destin, FL, April 8-12, 2002.

4. Povinelli, Louis A. and Yungster, Shaye, "Thermodynamic Cycle and CFD Analyses for Hydrogen Fueled AirBreathing Pulse Detonation Engines," NASA/TM-2002-211698, June 2002, also AIAA Paper 2002-3629, 38th AIAA/ASME/SAE/ASEE Joint Propulsion Conference, Indianapolis, Indiana, July 7-10, 2002.

5. Schauer, Fred, Stutrud, Jeff and Bradley, Royce, "Detonation Initiation Studies and Performance Results for Pulse Detonation Engine Applications," AIAA Paper 20011129.

6. Povinelli, Louis A., "Pulse Detonation Engines for High Speed Flight," NASA/ TM-2002-211908, Sept. 2002, also Paper 17-5169, 11th International AIAA/AAAF Conference on Space Planes and Hypersonic Systems and Technologies, September 29-October 4, 2002. Orleans, France.

7. Yungster, S. and Radhakrishnan, K., "A Fully Implicit Time Accurate Method for Hypersonic Combustion: Application to Shock Induced Combustion Instability," Shock Waves, Vol. 5, 1996, pp. 293-303.

8. Yungster, S. and Radhakrishnan, K., "Simulation of Unsteady Hypersonic
Combustion Around Projectiles in an Expansion Tube," Shock Waves, Vol. 11, 2001, pp. 167-177.

9. Li, S.C., Varatharajan, B. and Williams, F.A., "The Chemistry of Ethylene Ignition for Application to Pulse Detonation Engines," AIAA Paper 2000-3475 (A0036678), 36th AIAA/SAE/ASME/ASEE Joint Propulsion Conference, July 19, 2000, Huntsville, Alabama.

10. Gordon, S. and McBride, B., "Computer Program for Calculation of Complex Chemical Equilibrium Compositions and Applications," NASA Reference Publication 1311, Oct. 1994.

11. Wintenberger, E., Austin, J.M., Cooper, M., Jackson, S. and Shepard, J.E., "An Analytical Model for the Impulse of a Single-Cycle Pulse Detonation Engine," AIAA 2001-3811, A01-34455, 7th AIAA/ASME/SAE/ASEE Joint Propulsion Conference and Exhibit, July 8-11, 2001, Salt Lake City, UT.

12. Kailasanath, K., "A Review of PDE Research-Performance Estimates," AIAA 2000-0474, 39th AIAA Aerospace Sciences Meeting and Exhibit, January 8-11, 2001, Reno, NV.

13. Heiser, W.H. and Pratt, D.T., "Thermodynamic Cycle Analysis of Pulse Detonation Engines," Jrl. of Propulsion and Power, Vol. 18, No. 1, JanuaryFebruary 2002. 


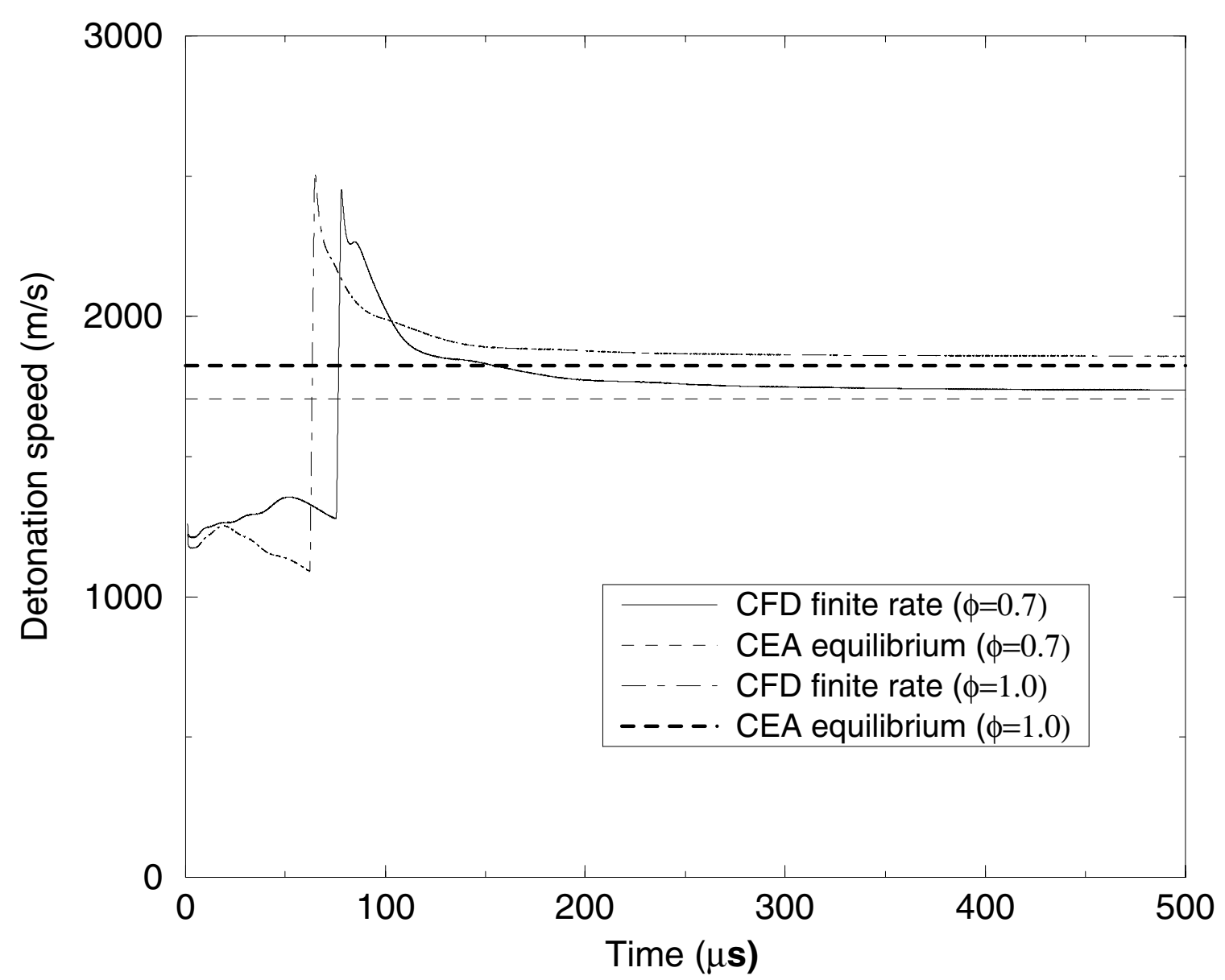

Figure 1. Detonation speed variation with time. Ethylene-air mixture, equivalence ratio 1.0, pressure 1 bar, temperature $298 \mathrm{~K}$. 


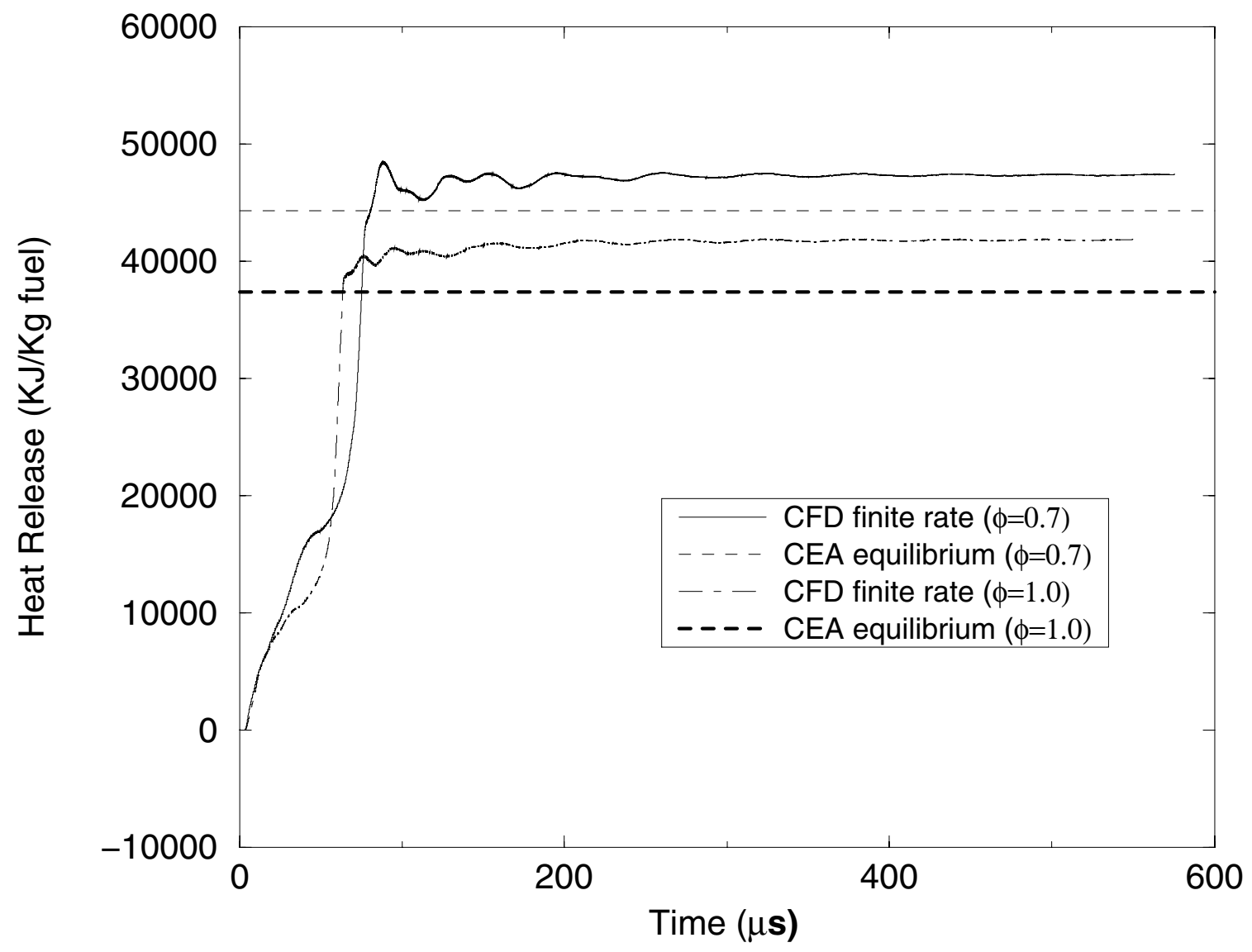

Figure 2. Heat release per unit mass of burned fuel as a function of time. Ethylene-air mixture, equivalence ratios 0.7 and 1.0 , pressure 1 bar, temperature $298 \mathrm{~K}$. 


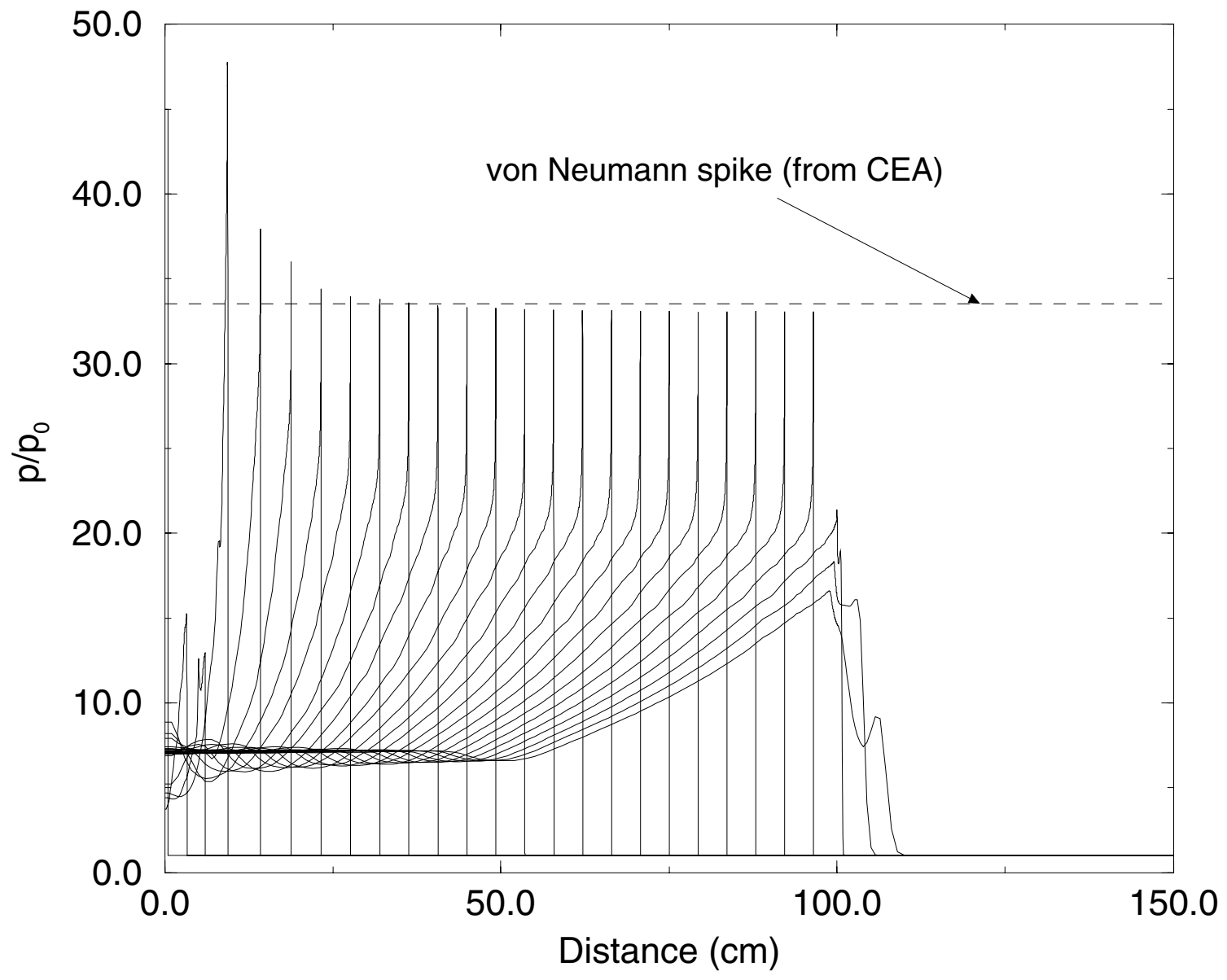

Figure 3. Pressure evolution traces. Equivalence ratio 1.0, pressure 1 bar, temperature $298 \mathrm{~K}$. 


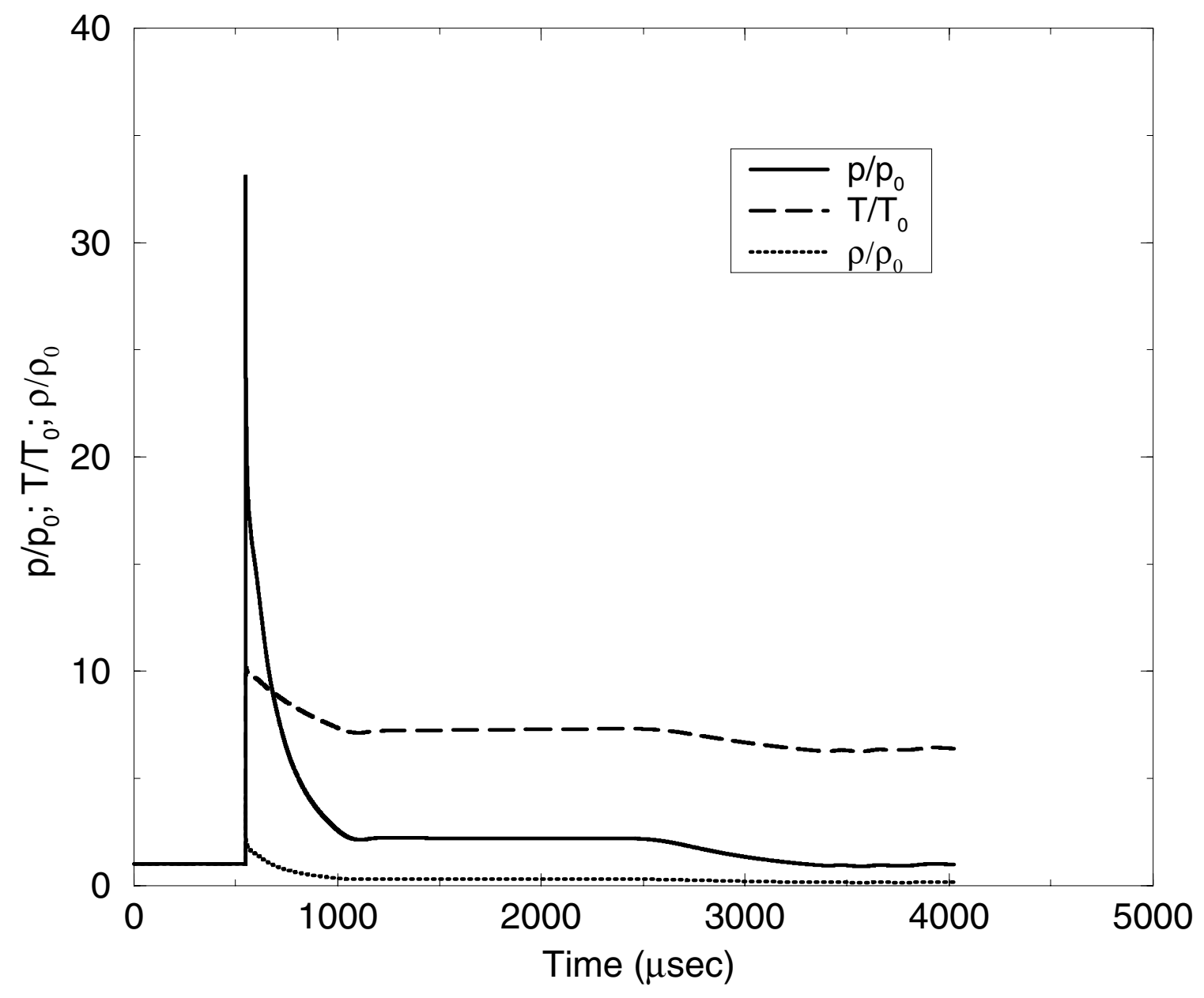

Figure 4. Flowfield conditions at the exit of detonation tube (1.0 meter) as a function of time, equivalence ratio 1.0 . 


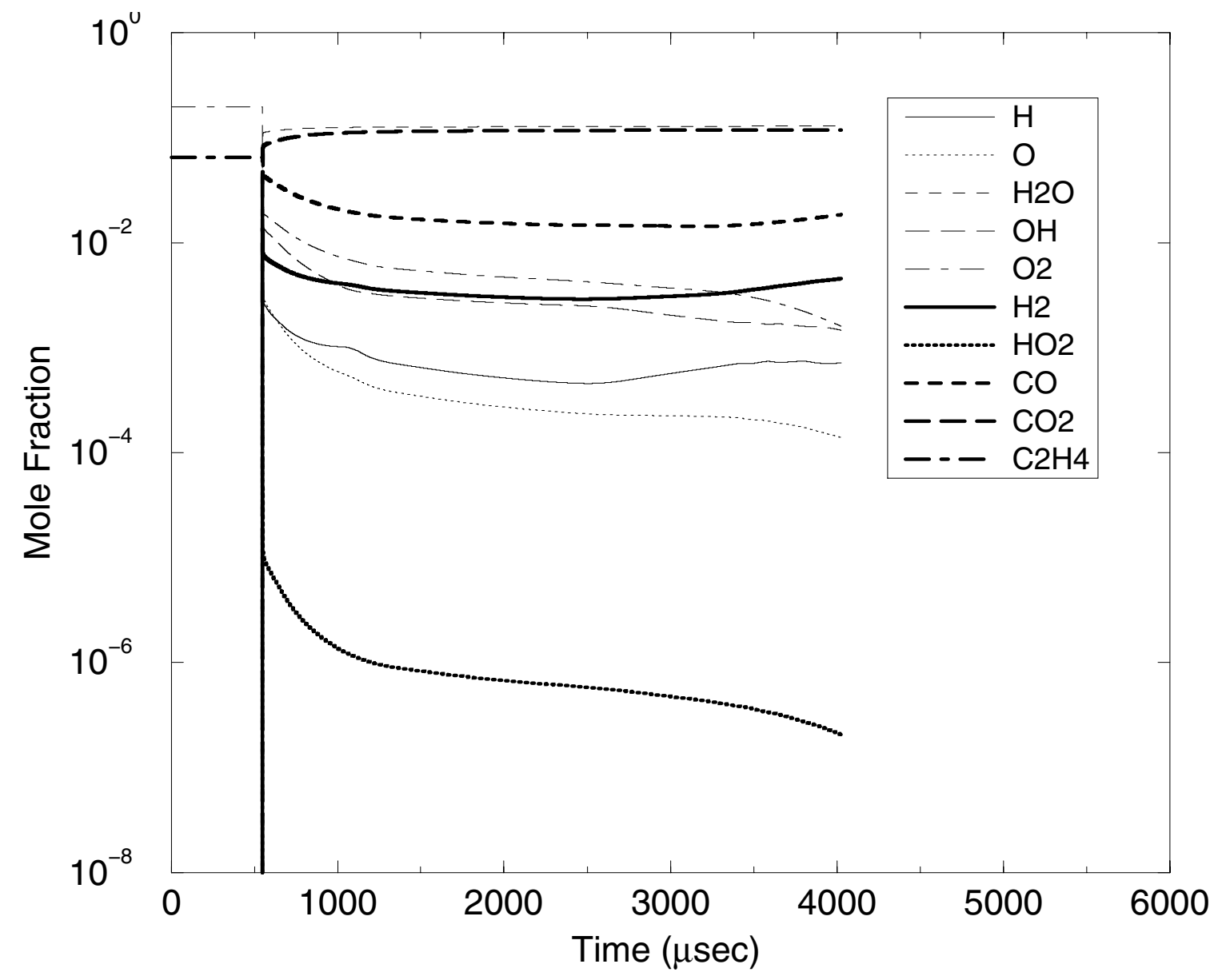

Figure 5. Species mole fractions at the exit of the detonation tube (1.0 meter) as a function of time, equivalence ratio 1.0. 


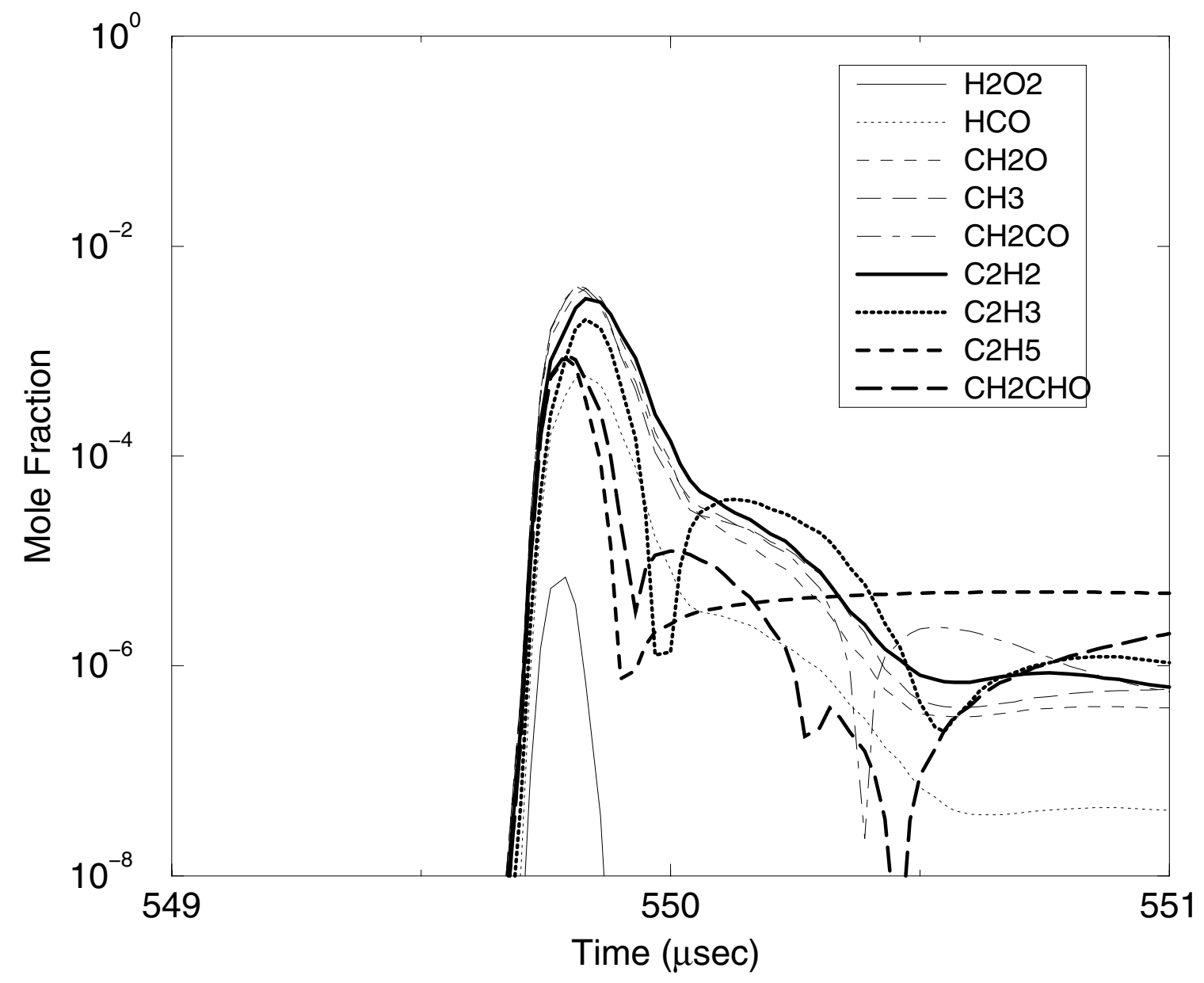

Figure 6. Species mole fractions at the exit of the detonation tube (1.0 meter) as a function of time, equivalence ratio 1.0. 


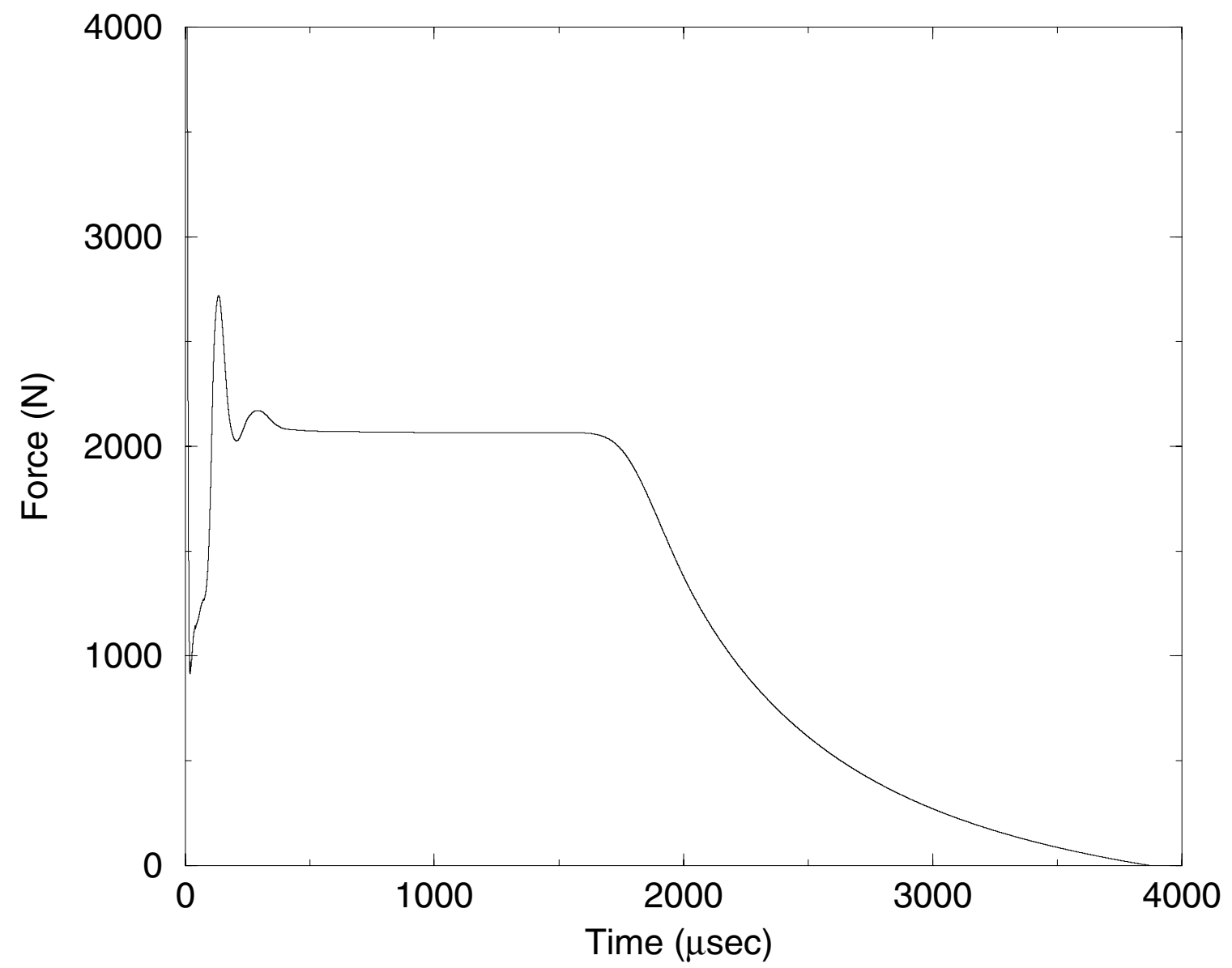

Figure 7. Force at the exit of the detonation tube (1.0 meter) for finite rate chemistry calculation. 


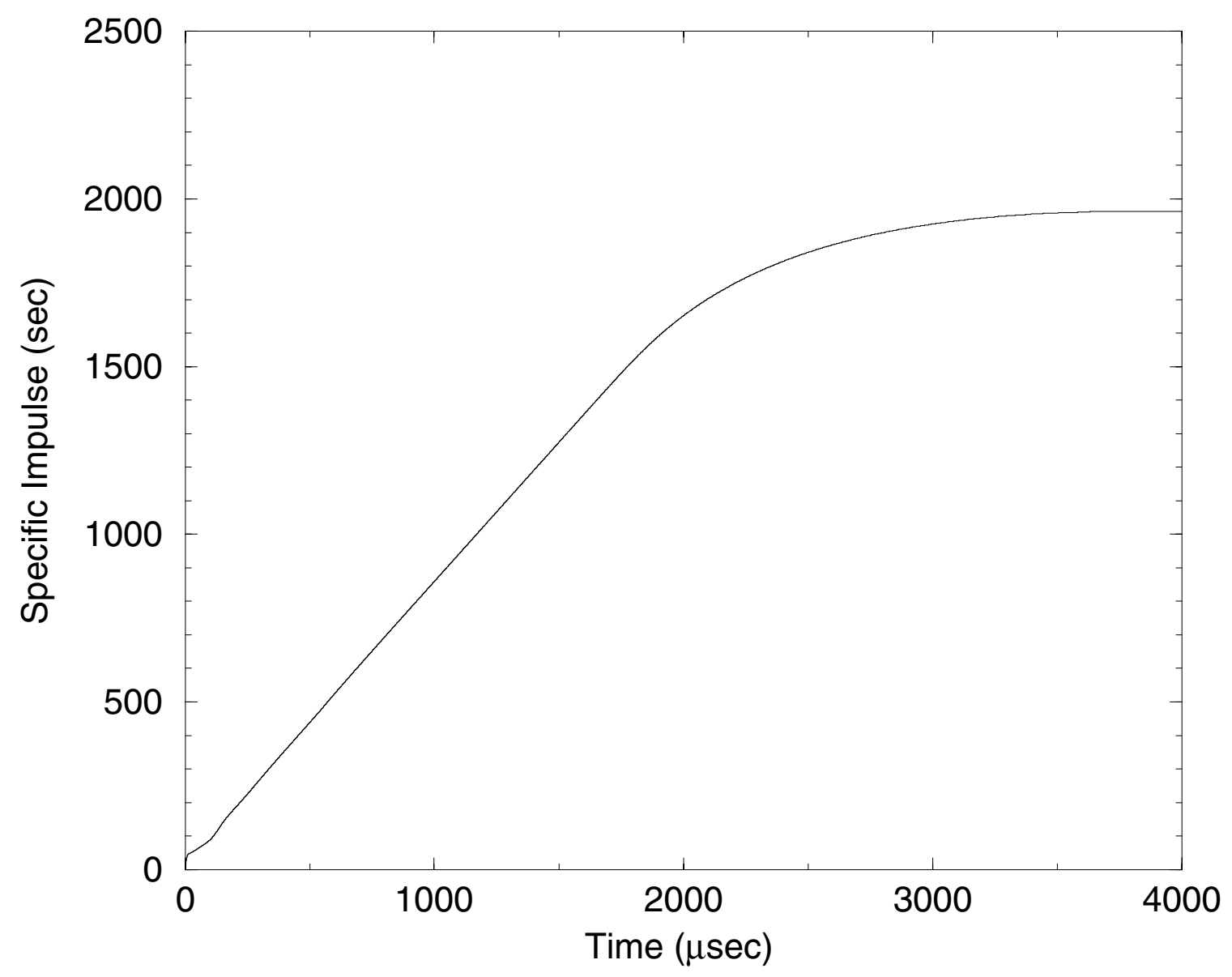

Figure 8. Specific Impulse at the exit of the detonation tube (1.0) meter for finite rate chemistry calculation. 

Public reporting burden for this collection of information is estimated to average 1 hour per response, including the time for reviewing instructions, searching existing data sources, gathering and maintaining the data needed, and completing and reviewing the collection of information. Send comments regarding this burden estimate or any other aspect of this collection of information, including suggestions for reducing this burden, to Washington Headquarters Services, Directorate for Information Operations and Reports, 1215 Jefferson Davis Highway, Suite 1204, Arlington, VA 22202-4302, and to the Office of Management and Budget, Paperwork Reduction Project (0704-0188), Washington, DC 20503.

\begin{tabular}{|l|l|l}
\hline 1. AGENCY USE ONLY (Leave blank) & $\begin{array}{c}\text { 2. REPORT DATE } \\
\text { March } 2003\end{array}$ & $\begin{array}{c}\text { 3. REPORT TYPE AND DATES COVERED } \\
\text { Technical Memorand }\end{array}$
\end{tabular}

\section{TITLE AND SUBTITLE}

5. FUNDING NUMBERS

Real Gas Effects on the Performance of Hydrocarbon-Fueled Pulse

Detonation Engines

6. AUTHOR(S)

Louis A. Povinelli and Shaye Yungster

7. PERFORMING ORGANIZATION NAME(S) AND ADDRESS(ES)

National Aeronautics and Space Administration

John H. Glenn Research Center at Lewis Field

Cleveland, Ohio 44135-3191

WBS-22-719-10-01

National Aeronautics and Space Administration

Washington, DC 20546-0001

8. PERFORMING ORGANIZATION REPORT NUMBER

E-13819

\section{SPONSORING/MONITORING AGENCY NAME(S) AND ADDRESS(ES)}

$$
\mathrm{E}-13819
$$

\section{SUPPLEMENTARY NOTES}

Prepared for the 41st Aerospace Sciences Meeting and Exhibit sponsored by the American Institute of Aeronautics and Astronautics, Reno, Nevada, January 6-9, 2003. Louis A. Povinelli, NASA Glenn Research Center; Shaye Yungster, Institute for Computational Mechanics in Propulsion, Cleveland, Ohio 44135. Responsible person, Louis A. Povinelli, organization code 5000, 216-433-5818.

\section{\begin{tabular}{|l|l}
\hline 12a. DISTRIBUTION/AVAILABILITY STATEMENT & 12b. DISTRIBUTION CODE
\end{tabular}}

Unclassified - Unlimited

Subject Category: 07

Distribution: Nonstandard

Available electronically at http://gltrs.grc.nasa.gov

This publication is available from the NASA Center for AeroSpace Information, 301-621-0390.

13. ABSTRACT (Maximum 200 words)

This paper presents results for a single-pulse detonation tube wherein the effects of high temperature dissociation and the subsequent recombination influence the sensible heat release available for providing propulsive thrust. The study involved the use of ethylene and air at equivalence ratios of 0.7 and 1.0. The real gas effects on the sensible heat release were found to be significantly large so as to have an impact on the thrust, impulse, and fuel consumption of a PDE.

\begin{tabular}{|c|c|c|}
\hline \multicolumn{3}{|c|}{$\begin{array}{l}\text { 14. SUBJECT TERMS } \\
\text { Propulsion; Detonation engines; PDE }\end{array}$} \\
\hline $\begin{array}{l}\text { 17. SECURITY CLASSIFICATION } \\
\text { OF REPORT } \\
\text { Unclassified }\end{array}$ & $\begin{array}{l}\text { 18. SECURITY CLASSIFICATION } \\
\text { OF THIS PAGE } \\
\text { Unclassified }\end{array}$ & $\begin{array}{l}\text { 19. SECURITY CLASSIFICATION } \\
\text { OF ABSTRACT } \\
\text { Unclassified }\end{array}$ \\
\hline
\end{tabular}

